\title{
Association of vitamin D insufficiency with adiposity and metabolic disorders in Brazilian adolescents
}

\author{
Renata MS Oliveira ${ }^{1, *}$, Juliana F Novaes ${ }^{2}$, Lorena M Azeredo², Ana Paula C Cândido' \\ and Isabel CG Leite ${ }^{3}$ \\ 'Department of Nutrition, Federal University of Juiz de Fora, Rua Antonio Altaf 150/201, Cascatinha 36033-330, \\ Juiz de Fora, Minas Gerais, Brazil: ${ }^{2}$ Department of Nutrition and Health, Federal University of Viçosa, Viçosa, \\ MG, Brazil: ${ }^{3}$ School of Medicine, Federal University of Juiz de Fora, Juiz de Fora, MG, Brazil
}

Submitted 27 September 2012: Final revision received 25 February 2013: Accepted 1 April 2013: First published online 9 May 2013

\begin{abstract}
Objective: The present study aimed to evaluate the frequency of deficiency/ insufficiency of vitamin D in adolescents and its relationship to overweight and metabolic disorders.

Design: Cross-sectional study. Nutritional status was assessed by BMI according to WHO recommendations. Dietary intake was evaluated using a $3 \mathrm{~d}$ dietary record. The biochemical evaluation comprised measurements of serum lipids, lipoproteins, glucose, insulin, calcidiol (25(OH)D) and parathyroid hormone. Insulin resistance was calculated using the homeostasis model assessment. Body composition and blood pressure were assessed.

Setting: Fifteen schools (eight public and seven private) in the central city of Juiz de Fora, Brazil.

Subjects: The analysis included a study population of 160 adolescents (seventyseven eutrophic and eighty-three overweight) aged 15 to 17 years.

Results: Vitamin D deficiency and insufficiency was observed in 1.25 and $70 \cdot 6 \%$ of adolescents, respectively. Serum 25(OH)D levels were statistically lower in adolescents with weight excess, abdominal obesity, hypercholesterolaemia, higher levels of parathyroid hormone, insulin resistance, hyperinsulinaemia and hypertension $(P<0 \cdot 05)$. Lower BMI and waist circumference were observed in the third (highest) tertile of vitamin D intake for all adolescents. The high prevalence of vitamin D insufficiency is primarily nutritional and reflects a low vitamin D intake. Conclusions: Our results support the negative association among serum 25(OH)D levels and vitamin D intake with non-skeletal outcomes in Brazilian adolescents. Vitamin D fortification of foods and/or the use of vitamin D supplements need to be considered to raise vitamin D intake in the adolescent population, even in a sunny country like Brazil.
\end{abstract}

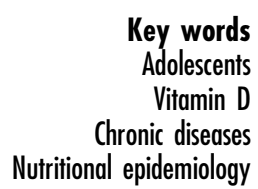

Vitamin D insufficiency/deficiency has been considered a public health problem worldwide because of its implications in the bone tissue, as well as in maintaining the normal homeostasis of $\mathrm{Ca}$ and $\mathrm{P}$ which is already well known ${ }^{(1-3)}$. In tropical countries this insufficiency/ deficiency has not been cited as a major concern, since cutaneous synthesis from sun exposure is the major source of vitamin D in most individuals. However, some studies have reported a significant insufficiency/deficiency prevalence even in countries with adequate sun exposure, as in the case of Brazil $^{(4,5)}$. Peters et al ${ }^{(5)}$ reported that $60 \%$ of adolescents from the state of São Paulo had vitamin D insufficiency, despite having collected their data during the summer.

An adequate vitamin D level is essential in all stages of life, and there is consensus that the best status indicator of this vitamin is the serum concentration of calcidiol $(25(\mathrm{OH}) \mathrm{D})^{(3)}$. Low levels of calcidiol directly affect Ca absorption and bone mineralization. However, recent studies have indicated that deficiency of this vitamin may confer a risk factor for the development of endocrine and metabolic diseases ${ }^{(6,7)}$. Studies suggest that vitamin D may be involved in various processes, such as cell differentiation/proliferation and hormone secretion, as well as in the immune system and in chronic diseases such as obesity, glucose intolerance, increased blood pressure and lipid abnormalities ${ }^{(7-9)}$

Despite the scientific interest in the topic, most studies investigating the consequences of hypovitaminosis D in relation to metabolic disorders have focused their attention on adults and the elderly. However, it is necessary to consider that adolescence is the strategic period for 
promoting healthy habits and preventing the development of overweight/obesity, which damages the current physical and mental health of the individual ${ }^{(10)}$, besides being considered a predictor of overweight in adulthood, atherosclerotic disease, hypertension and metabolic disorders ${ }^{(11)}$.

In Brazil, while the accelerating increase of overweight/ obesity in adolescence has been reported in national studies $^{(12)}$, there are few studies aimed at investigating the vitamin D status of healthy adolescents. Considering the impact on the metabolic profile of health, the present study aimed to evaluate the frequency of deficiency/insufficiency of vitamin D in adolescents and its relationship to overweight and metabolic disorders.

\section{Methods}

The study was cross-sectional, conducted with eutrophic and overweight adolescents aged 15 to 17 years from high schools in the city of Juiz de Fora.

\section{Study design}

The city of Juiz de Fora, located in the region of Minas Gerais in south-east Brazil, had a population of 497778 inhabitants of whom 487822 (98\%) lived in the urban area in $2010^{(13)}$.

The sample size was calculated using the following premises: population size of adolescents aged 15-17 years in Juiz de Fora of $18814^{(14)}$, prevalence of vitamin D insufficiency of $62 \%{ }^{(5)}$, error tolerance of $8 \%, 95 \%$ confidence interval, significance level of $5 \%$ and estimated loss of $10 \%$, resulting in a total of 165 adolescents. Participating schools were selected based on calculating the number of public and private institutions needed to represent the region (fifteen schools). All adolescents in the age group of the study, enrolled in selected schools, were invited to participate in nutritional status screening to evaluate their nutritional status. By random selection and based on the study inclusion criteria (non-use of drugs interfering with glucose and lipid metabolism, non-use of supplemental Ca and/or vitamin D, not pregnant/lactating and having already experienced menarche for girls ${ }^{(15)}$, presence of axillary and facial hair for boys ${ }^{(16)}$ ), the authors contacted eighty-three pairs of adolescents (one eutrophic and one overweight). Six adolescents declined participation because they were already in nutritional monitoring with other professionals. Thus, a sample of 160 adolescents were eligible to participate in the study, with seventy-seven being eutrophic $(\mathrm{BMI}<85$ th percentile for age and sex) and eighty-three overweight (BMI $\geq 85$ th percentile). The groups were similar in age, gender and type of school (public or private).

\section{Antbropometry and body composition}

Weight was taken on a digital electronic scale (Tanita ${ }^{\circledR}$ model BC 553, Arlington Heights, IL, USA), with a maximum capacity of $150 \mathrm{~kg}$ and $100 \mathrm{~g}$ graduations, and height using a portable stadiometer (Alturexata ${ }^{\circledR}$, Belo Horizonte, MG, Brazil) with a height range of $2 \mathrm{~m}$, in $0 \cdot 1 \mathrm{~cm}$ graduations. Weight and height were measured according to the techniques advocated by Jellife ${ }^{(17)}$. Nutritional status was assessed by BMI according the WHO recommendations ${ }^{(18)}$. Excessive weight was defined as BMI above $1 \mathrm{SD}$.

Waist circumference (WC) was measured with a nonelastic flexible tape $\left(\mathrm{TBW}^{\circledR}\right.$, São Paulo, SP, Brazil) with the adolescent in a standing position, at the end of expiration $^{(17)}$. Abdominal adiposity was estimated using cut-off points corresponding to the 90th centiles ${ }^{(19)}$.

Percentage of body fat (\%BF) was estimated from the resistance and reactance values provided by a horizontal tetrapolar bioimpedance analyser (Biodynamics ${ }^{\circledR}$ model 310, Seattle, WA, USA). For this measure, adolescents followed the protocol ${ }^{(20)}$. The values provided by the bioimpedance analyser were used in the equation proposed by Houtkooper et $a l^{(21)}$. \%BF was analysed according to the classification proposed by Lohman ${ }^{(22)}$.

\section{Biochemical and clinical assessment}

Blood samples were collected at the schools by technically qualified professionals and analysed in the Clinical Analysis Laboratory at the University Hospital, Federal University of Juiz de Fora. The samples were collected by venepuncture in the antecubital region, from individuals who had fasted for $12 \mathrm{~h}$, to measure plasma glucose, insulin, total cholesterol (TC), HDL-cholesterol (HDL-C), LDL-cholesterol (LDL-C), TAG, 25(OH)D and parathyroid hormone (PTH).

Blood lipids were analysed according to the Brazilian Cardiology Society ${ }^{(23)}$. Impaired glucose tolerance was analysed according to the American Diabetes Association ${ }^{(24)}$. Fasting plasma insulin $\geq 15 \mu \mathrm{U} / \mathrm{ml}$ was considered hyperinsulinaemia $^{(23)}$. Insulin resistance was assessed using the homeostasis model assessment (HOMA-IR), with HOMA-IR $\geq 3 \cdot 16$ being considered the presence of insulin resistance ${ }^{(23)}$.

Serum $25(\mathrm{OH}) \mathrm{D}$ levels were considered the most useful marker of total vitamin D exposure from both endogenous synthesis and dietary intake. Serum 25(OH)D levels were measured by a RIA kit. The cut-off points used to classify vitamin $\mathrm{D}$ deficiency and insufficiency were $\leq 25 \mathrm{nmol} / \mathrm{l}$ $(\leq 10 \mathrm{ng} / \mathrm{ml})$ and between 25 and $75 \mathrm{nmol} / 1(10-30 \mathrm{ng} / \mathrm{ml})$, respectively ${ }^{(25)}$. The intact PTH level was measured by a chemiluminescence immunoassay, with values between 15 and $65 \mathrm{pg} / \mathrm{ml}$ being considered normal ${ }^{(5)}$.

Sitting blood pressure was measured using an automatic unit with the right arm at the same level as the heart, using an appropriate cuff size. This equipment (Omron ${ }^{\circledR}$ HEM 907, Vernon Hills, IL, USA) was validated against mercury sphygmomanometers according to the international validation protocol ${ }^{(26)}$. Blood pressure was measured three times at 5 min intervals and was considered the average of the second and third measurements. The classification individually took into account 
gender, age and height based on parameters of the Brazilian Hypertension Society ${ }^{(27)}$.

\section{Dietary assessment}

Dietary intake was assessed by a $3 \mathrm{~d}$ food record, obtained over three non-consecutive days, one on the weekend $^{(28)}$. The food record method for evaluation of nutrient intakes was used because of its high specificity in describing foods and food preparation methods ${ }^{(27)}$. The adolescents were informed about self-reporting the food records, with the food consumed being recorded in household measures, as well as the brand of the manufactured product. When an adolescent returned his/her records, a dietitian checked the record contents using photo albums and clarified the information with the adolescent. Standardization of recipes and portion sizes was carried out in order to analyse the results ${ }^{(29,30)}$.

Nutrient intakes were calculated using Diet-Pro software version $4 \cdot 0$. The foods or preparations that did not appear in the software's database were inserted according to data from tables of food composition ${ }^{(29,30)}$ and food labels. The assessment of adequate vitamin D intake was carried out following the recommendations from the Dietary Reference Intakes (DRI) ${ }^{(31)}$. To control the effect of energy consumption on the micronutrients evaluated, we used the nutrient residual method proposed by Willett and Stampfer ${ }^{(28)}$.

\section{Physical activity and sun exposure}

Physical activity was assessed using the questionnaire developed and validated for adolescents by Florindo et $a l^{(32)}$, which allows the calculation of a weekly physical activity score. To classify the level of physical activity, we used the final score as a dichotomous variable, using the cut-off point of $\geq 300 \mathrm{~min} /$ week as moderate or vigorous physical activity and $<300 \mathrm{~min} /$ week as light or sedentary physical activity ${ }^{(33)}$.

Sun exposure was evaluated by asking whether the adolescents used sunscreen daily (yes or no), and if they performed outdoor physical activities (yes or no) and their frequency ( $\mathrm{min} /$ week).

Data were collected by trained staff at the schools participating in the project. A room was properly assembled and equipped for this purpose.

\section{Statistical analysis}

The database construction and statistical analyses were done using the statistical software package SPSS for Windows version $17 \cdot 0$.

The Kolmogorov-Smirnov normality test was used to determine if the distribution of values was normal in all variables. According to the distribution of variables in the normal curve, Student's $t$ test, the Mann-Whitney test, the Kruskal-Wallis test and ANOVA were used to compare two or three groups. When a statistical difference was detected among three groups, Bonferroni's test and Tukey's test were then performed to assess specific differences. Pearson or Spearman correlation tests were also employed.

\section{Results}

A total of 160 adolescents were evaluated in the present study. Their mean age was 16 years, 55.6\% were male, $48 \cdot 1 \%$ were eutrophic and $51.9 \%$ were overweight.

The characteristics of the population, overall and by nutritional status, are presented in Table 1. Adolescents with excess weight had significantly higher mean values of WC, \%BF, TC, LDL-C, TAG, insulin, HOMA-IR, systolic and diastolic blood pressure $(P<0 \cdot 05)$. Lower mean serum levels of $25(\mathrm{OH}) \mathrm{D}$ and HDL-C were found in the excess weight group $(P<0 \cdot 05$; Table 1$)$. Higher prevalence of hypercholesterolaemia, hypertriacylglycerolaemia, hyperinsulinaemia, reduced HDL-C, systolic and diastolic hypertension was found in the excess weight group $(P<0 \cdot 05)$.

The mean serum 25(OH)D level was $24 \cdot 0 \mathrm{nmol} / 1$. Vitamin D deficiency was observed in $1.25 \%(n 2)$ of the adolescents, both from the excess weight group. Insufficiency was observed in $70 \cdot 6 \%$ of the adolescents $(72 \cdot 2$ and $68 \cdot 8 \%$ from the normal and excess weight groups, respectively).

No statistical difference in vitamin D intake, demographic and behavioural variables was observed according to serum 25(OH)D level. Serum 25(OH)D levels were statistically lower in adolescents with excess body fat, abdominal obesity, hypercholesterolaemia, insulin resistance, hyperinsulinaemia and hypertension $(P<0.05$; Table 2). Furthermore, the levels of serum 25(OH)D had a significant inverse correlation with BMI, WC, \%BF, TC, LDL-C, insulin, HOMA-IR and PTH $(P<0 \cdot 05)$.

Daily sunscreen use and the practice of physical activities in sunlight were reported by $16 \cdot 2$ and $31.5 \%$ of the adolescents, respectively. The mean duration of physical activities in sunlight was $80 \mathrm{~min} /$ week. There was no difference in serum $25(\mathrm{OH}) \mathrm{D}$ concentration between adolescents who did/did not use sunscreen daily, nor between adolescents who did/did not practise physical activity in sunlight. These behaviours did not differ between adolescents with or without excess weight.

The macronutrient distribution was adequate according to the Acceptable Macronutrient Distribution Ranges ${ }^{(34)}$ in eutrophic and overweight adolescents. No differences in energy, protein, fat, $\mathrm{Ca}$, saturated fat and cholesterol intakes were observed between groups. Significantly more adolescents with excess weight had low vitamin D and carbohydrate intakes compared with the eutrophic group $(P=0.009$ and $P=0 \cdot 015$, respectively).

The mean vitamin D intake $(2 \cdot 18 \mu \mathrm{g} / \mathrm{d})$ was lower than the Estimated Average Requirement (EAR) in both groups. The main sources of vitamin D reported by teenagers were milk, eggs and butter. This intake did not differ between adolescents with and without excess weight, and 
Table 1 Distribution of anthropometry, body composition, biochemical profile and clinical characteristics according to nutritional status among adolescents $(n 160)$ aged 15 to 17 years, Juiz de Fora city, Brazil

\begin{tabular}{|c|c|c|c|c|c|}
\hline \multirow[b]{2}{*}{ Variable } & \multicolumn{2}{|c|}{ Eutrophic } & \multicolumn{2}{|c|}{ Overweight } & \multirow[b]{2}{*}{$P$ value } \\
\hline & Mean or median & SD or IQR & Mean or median & SD or IQR & \\
\hline Age (years)† & $16 \cdot 0$ & 0.9 & $16 \cdot 0$ & $0 \cdot 8$ & 0.644 \\
\hline Weight (kg) & $58 \cdot 4$ & $0 \cdot 4$ & $83 \cdot 4$ & $17 \cdot 8$ & $<0.001^{*}$ \\
\hline Height $(\mathrm{cm}) \dagger$ & $168 \cdot 9$ & $1 \cdot 0$ & $169 \cdot 6$ & $1 \cdot 0$ & 0.629 \\
\hline BMI $\left(\mathrm{kg} / \mathrm{m}^{2}\right)$ & $20 \cdot 4$ & $2 \cdot 9$ & $29 \cdot 0$ & $5 \cdot 0$ & $<0.001^{*}$ \\
\hline WC $(\mathrm{cm})$ & $67 \cdot 0$ & $6 \cdot 0$ & $87 \cdot 0$ & $13 \cdot 0$ & $<0.001^{*}$ \\
\hline$\% B F$ & $22 \cdot 3$ & $3 \cdot 2$ & $32 \cdot 5$ & $9 \cdot 0$ & $<0.001^{*}$ \\
\hline FFM (kg)† & $45 \cdot 2$ & 0.9 & $57 \cdot 4$ & $1 \cdot 0$ & $<0.001^{*}$ \\
\hline Fat $(\mathrm{kg})$ & $12 \cdot 7$ & $7 \cdot 2$ & $26 \cdot 5$ & $11 \cdot 9$ & $<0.001^{*}$ \\
\hline TC $(\mathrm{mg} / \mathrm{dl}) \dagger$ & $161 \cdot 8$ & $3 \cdot 7$ & $175 \cdot 2$ & $3 \cdot 7$ & $0 \cdot 013^{*}$ \\
\hline HDL-C (mg/dl)† & $53 \cdot 6$ & $1 \cdot 0$ & $47 \cdot 2$ & $1 \cdot 1$ & $<0.001^{*}$ \\
\hline LDL-C (mg/dl) & $88 \cdot 0$ & $41 \cdot 0$ & $109 \cdot 3$ & $5 \cdot 0$ & $<0.001^{*}$ \\
\hline TAG $(\mathrm{mg} / \mathrm{dl})$ & $68 \cdot 0$ & $1 \cdot 0$ & $79 \cdot 0$ & $56 \cdot 0$ & $0.021^{*}$ \\
\hline Glucose (mg/dl)† & $85 \cdot 2$ & 0.9 & $83 \cdot 9$ & $1 \cdot 0$ & $0 \cdot 383$ \\
\hline Insulin (U/ml) & 8.9 & $3 \cdot 4$ & $10 \cdot 6$ & $6 \cdot 2$ & $<0.001^{*}$ \\
\hline HOMA-IR & $1 \cdot 7$ & 0.9 & $2 \cdot 4$ & 1.5 & $<0.001^{*}$ \\
\hline 25(OH)D (nmol/l) & $25 \cdot 5$ & $15 \cdot 0$ & $22 \cdot 2$ & $10 \cdot 4$ & $0.005^{\star}$ \\
\hline $\mathrm{PTH}_{\mathrm{i}}(\mathrm{nmol} / \mathrm{l})$ & $40 \cdot 0$ & $22 \cdot 3$ & $42 \cdot 3$ & $20 \cdot 0$ & 0.208 \\
\hline SBP $(\mathrm{mmHg}) \dagger$ & $113 \cdot 6$ & $1 \cdot 3$ & $126 \cdot 5$ & $1 \cdot 3$ & $<0.001^{*}$ \\
\hline $\mathrm{DBP}(\mathrm{mmHg})$ & $69 \cdot 6$ & $11 \cdot 0$ & $75 \cdot 3$ & $11 \cdot 0$ & $<0.001^{*}$ \\
\hline
\end{tabular}

IQR, interquartile range; WC, waist circumference; \%BF, percentage of body fat; FFM, fat-free mass; TC, total cholesterol; HDL-C, HDL-cholesterol; LDL-C, LDL-cholesterol; HOMA-IR, homeostasis model assessment of insulin resistance; $25(\mathrm{OH}) \mathrm{D}$, calcidiol; PTH $\mathrm{H}_{\mathrm{i}}$, intact parathyroid hormone; SBP, systolic blood pressure; DBP, diastolic blood pressure.

${ }^{\star}$ Significant result.

tThese variables were parametric (mean and standard deviation) and compared between groups using Student's $t$ test; otherwise, variables were nonparametric (median and IQR) and compared between groups using the Mann-Whitney test.

daily milk consumption was reported by only $57 \%$ of the adolescents. Only $7 \cdot 2 \%$ of the excess weight group and $15.6 \%$ of the eutrophic group reached the EAR for vitamin D $(10 \mu \mathrm{g} / \mathrm{d})$. Lower BMI and WC were observed in the third (highest) tertile of vitamin D intake for all adolescents $(P<0 \cdot 05$; Table 3$)$. There was no statistical correlation between vitamin $\mathrm{D}$ intake and serum 25(OH)D level $(r=0 \cdot 151 ; P=0 \cdot 56)$.

\section{Discussion}

The present study found that a significant proportion $(\sim 70 \%)$ of Brazilian adolescents had vitamin D insufficiency even in a tropical country. These results are lower than those observed by Delvin et $a l^{(35)}$ who, in an evaluation of Canadian children and adolescents, and using the same proposed classification of $25(\mathrm{OH}) \mathrm{D}$ levels, found a $93 \%$ rate of suboptimal levels of this vitamin. In Brazil, until the present day, there are few studies on the prevalence of hypovitaminosis $\mathrm{D}$ in adolescence. Peters et al. ${ }^{(5)}$ studied healthy adolescents in São Paulo and observed a $62 \cdot 1 \%$ rate of insufficiency using the same proposed classification of $25(\mathrm{OH}) \mathrm{D}$ levels. These results indicate that although hypovitaminosis $\mathrm{D}$ is lower in Brazil due to the tropical climate, a significant prevalence of insufficiency of this vitamin is seen when compared with milder climates.

In the present study, the serum 25(OH)D levels were statistically lower in adolescents with excess weight, abdominal obesity, hypercholesterolaemia, insulin resistance, hyperinsulinaemia and hypertension $(P<0 \cdot 05)$. The lower serum 25(OH)D levels in overweight individuals has been reported previously in the scientific literature $^{(8,9,35)}$. It is believed that low serum vitamin D levels in the obese are not just a consequence of reduced sun exposure. Some evidence suggests that this deficiency may be linked to vitamin D storage in adipocytes, decreasing its bioavailability and activating the hypothalamus to develop a cascade of reactions that results in increased feelings of hunger and decreased energy expenditure ${ }^{(36)}$. This situation can also generate increased levels of PTH and a consequent decrease in insulin sensitivity ${ }^{(9)}$.

The inadequacy of the lipid profile observed in the present study has been described by the WHO as a problem in this age group in a number of countries ${ }^{(10)}$. It is noteworthy that the result showing the association of BMI with clinical and biochemical variables indicates the need for constant intervention with adolescents, thus reinforcing the importance of specific health care for this age group $^{(37)}$.

Several authors have discussed an extra-skeletal function of vitamin $\mathrm{D}$ and found that individuals with high levels of TC, LDL-C, insulin and blood pressure had serum $25(\mathrm{OH}) \mathrm{D}$ concentrations statistically lower than those with normal levels of these variables ${ }^{(6,7,35)}$. Kelly et al. ${ }^{(9)}$, studying the association of serum 25(OH)D levels and glucose profiles in obese and non-obese children, found that low vitamin D levels were associated with increased plasma insulin and insulin resistance after 
Table 2 Serum 25(OH)D levels according to demographic, behavioural and intake variables among adolescents aged 15 to 17 years, Juiz de Fora city, Brazil

\begin{tabular}{|c|c|c|c|c|}
\hline \multirow[b]{2}{*}{ Variable } & \multirow[b]{2}{*}{$\%$} & \multicolumn{2}{|c|}{$\begin{array}{l}\text { Serum } 25(\mathrm{OH}) \mathrm{D} \text { level } \\
(\mathrm{nmol} / \mathrm{l})\end{array}$} & \multirow[b]{2}{*}{$P$ value } \\
\hline & & Median & IQR & \\
\hline Sex & & & & $0 \cdot 150$ \\
\hline Female & $44 \cdot 4$ & $24 \cdot 8$ & $12 \cdot 8$ & \\
\hline Male & $55 \cdot 6$ & $22 \cdot 1$ & 11.5 & \\
\hline Age (years)† & & & & 0.738 \\
\hline 15 & $28 \cdot 7$ & $23 \cdot 4$ & $2 \cdot 7$ & \\
\hline 16 & $36 \cdot 9$ & $24 \cdot 7$ & $2 \cdot 9$ & \\
\hline 17 & $34 \cdot 4$ & $24 \cdot 1$ & $0 \cdot 1$ & \\
\hline Physical activity & & & & 0.854 \\
\hline Active & $61 \cdot 9$ & $24 \cdot 0$ & $12 \cdot 6$ & \\
\hline Sedentary & $38 \cdot 1$ & $24 \cdot 1$ & $10 \cdot 3$ & \\
\hline Vitamin D intake & & & & 0.886 \\
\hline$\geq 5 \mu \mathrm{g} / \mathrm{d}$ & $1 \cdot 2$ & $26 \cdot 9$ & $13 \cdot 7$ & \\
\hline$<5 \mu \mathrm{g} / \mathrm{d}$ & $88 \cdot 8$ & $26 \cdot 5$ & $1 \cdot 0$ & \\
\hline \%BFt & & & & $0.016^{\star}$ \\
\hline Eutrophic & $25 \cdot 6$ & $24 \cdot 9^{a}$ & $15 \cdot 5$ & \\
\hline Overweight & $23 \cdot 1$ & $27 \cdot 6^{\mathrm{a}}$ & $14 \cdot 9$ & \\
\hline Obese & $51 \cdot 3$ & $22 \cdot 6^{b}$ & $22 \cdot 6$ & \\
\hline WC (cm) & & & & 0.005 \\
\hline$<90$ th percentile & $83 \cdot 1$ & $24 \cdot 9$ & $12 \cdot 9$ & \\
\hline$\geq 90$ th percentile & $16 \cdot 9$ & $20 \cdot 3$ & $10 \cdot 8$ & \\
\hline Height (cm) & & & & $0 \cdot 044^{x}$ \\
\hline$\geq 10$ th percentile & $91 \cdot 9$ & $24 \cdot 8$ & $12 \cdot 8$ & \\
\hline$<10$ th percentile & $8 \cdot 1$ & $19 \cdot 8$ & $6 \cdot 8$ & \\
\hline TC (mg/dl) & & & & $0.011^{*}$ \\
\hline$<150$ & $53 \cdot 8$ & $25 \cdot 6$ & $13 \cdot 1$ & \\
\hline$\geq 150$ & $46 \cdot 2$ & $21 \cdot 6$ & $11 \cdot 3$ & \\
\hline HDL-C (mg/dl) & & & & 0.941 \\
\hline$\geq 45$ & $71 \cdot 2$ & $22 \cdot 9$ & $10 \cdot 2$ & \\
\hline$<45$ & $28 \cdot 8$ & $24 \cdot 9$ & $15 \cdot 0$ & \\
\hline LDL-C (mg/dl) & & & & 0.057 \\
\hline$<100$ & $84 \cdot 4$ & $24 \cdot 8$ & $12 \cdot 6$ & \\
\hline$\geq 100$ & $15 \cdot 6$ & $22 \cdot 1$ & $11 \cdot 0$ & \\
\hline TAG (mg/dl) & & & & $0 \cdot 110$ \\
\hline$<130$ & 86.9 & $24 \cdot 7$ & $12 \cdot 7$ & \\
\hline$\geq 130$ & $13 \cdot 1$ & $21 \cdot 7$ & $14 \cdot 7$ & \\
\hline $\mathrm{PTH}_{\mathrm{i}}(\mathrm{nmol} / \mathrm{l})$ & & & & 0.088 \\
\hline$<65$ & $87 \cdot 5$ & $24 \cdot 7$ & $11 \cdot 2$ & \\
\hline$\geq 65$ & $12 \cdot 5$ & $20 \cdot 2$ & $14 \cdot 8$ & \\
\hline Glucose (mg/dl) & & & & 0.471 \\
\hline$\leq 99$ & $97 \cdot 5$ & $24 \cdot 0$ & $11 \cdot 8$ & \\
\hline$>99$ & $2 \cdot 5$ & $31 \cdot 9$ & $29 \cdot 4$ & \\
\hline HOMA-IR & & & & $<0.001$ \\
\hline$\leq 3 \cdot 16$ & $86 \cdot 3$ & $25 \cdot 2$ & $13 \cdot 1$ & \\
\hline$>3 \cdot 16$ & $13 \cdot 7$ & $19 \cdot 3$ & $6 \cdot 6$ & \\
\hline Insulin $(\mu \mathrm{U} / \mathrm{ml})$ & & & & $<0.001^{\star}$ \\
\hline$\leq 15$ & $86 \cdot 3$ & $25 \cdot 6$ & $12 \cdot 7$ & \\
\hline$>15$ & $13 \cdot 7$ & $18 \cdot 6$ & $5 \cdot 2$ & \\
\hline $\mathrm{BP}(\mathrm{mmHg})$ & & & & $0 \cdot 017^{\star}$ \\
\hline$<90$ th percentile & $68 \cdot 1$ & $24 \cdot 9$ & $13 \cdot 2$ & \\
\hline$\geq 90$ th percentile & $31 \cdot 9$ & $21 \cdot 3$ & $10 \cdot 4$ & \\
\hline
\end{tabular}

25(OH)D, calcidiol; IQR, interquartile range; \%BF, percentage of body fat WC, waist circumference; TC, total cholesterol; HDL-C, HDL-cholesterol; LDL-C, LDL-cholesterol; PTH ${ }_{i}$, intact parathyroid hormone; HOMA-IR, homeostasis model assessment of insulin resistance; BP, blood pressure. ${ }_{\mathrm{a}, \mathrm{b}}$ Median values within a column with unlike superscript letters were significantly different $(P<0 \cdot 05)$.

*Significant result.

tThese values were compared between groups using the Kruskal-Wallis test; otherwise, the Mann-Whitney test was used.

adjustment for BMI and puberty. Some authors have observed that lower serum 25(OH)D levels are associated with blood pressure ${ }^{(5,3)}$. However, caution is needed before assuming any direct association. It is essential to consider the well-known influence between high BMI and excess weight, biochemical profile and blood pressure ${ }^{(11,38)}$.

The Institute of Medicine reviewed the DRI for vitamin D and concluded that a causal role of vitamin D in skeletal health provided the necessary basis for the EAR and RDA. However, for non-skeletal outcomes including CVD, diabetes and autoimmune disorders, the evidence was inconsistent and inconclusive as to causality, and insufficient for DRI development ${ }^{(30,39)}$. The mean vitamin D intake was lower than the EAR values in both groups in the present study; mean dietary vitamin D intake was inadequate for adolescents either with or without excess weight, and was significantly lower in adolescents with excess weight. Lower BMI and WC were observed in the third tertile of vitamin D intake for all adolescents $(P<0 \cdot 05)$.

The low vitamin $\mathrm{D}$ intake among adolescents has also been documented in other countries ${ }^{(5,40)}$. The dietary sources of vitamin D are limited, and food sources such as salmon, tuna and cod-liver oil are not usually consumed by Brazilian teenagers. The exception is milk, a food source consumed on a regular basis, where daily consumption was reported by $57 \%$ of adolescents. Furthermore, the unhealthy eating habits common at this stage of life, such as the habit of skipping breakfast, high consumption of soft drinks and processed products rather than foods that are sources of vitamins and minerals, and replacing dinner with snacks, can explain the reduction of these nutrients in the diet ${ }^{(11)}$. There was no association between vitamin $\mathrm{D}$ intake and serum 25(OH)D levels. The limitations of the food composition tables that comprise the databases in the dietary assessment software may have contributed to this result.

The other potential dietary source of vitamin D intake is supplements. However, none of the adolescents in our study were taking any vitamin D supplements. The use of supplements and foods fortified with vitamin D is not common in Brazil. In the present study, the fact that a substantial proportion of Brazilian adolescents had vitamin $\mathrm{D}$ insufficiency indicated that dietary sources of vitamin $\mathrm{D}$ are not adequate to maintain the recommended levels of vitamin D status. Similar results have been documented in a study conducted in São Paulo, Brazil ${ }^{(5)}$.

In addition to dietary vitamin $\mathrm{D}$ intake and supplements, the other source of vitamin D is exposure of the skin to sunlight. However, there was no difference in serum 25(OH)D concentration between adolescents who do/do not use sunscreen daily, as well as between adolescents who do/do not practise physical activity in sunlight. These behaviours did not differ between adolescents with or without excess weight.

Some limitations of the present study should be considered. It is noteworthy that, although using a random sample, the study is not representative of the whole population and so extrapolation of the results must be made with caution. However, the authors believe that the results are important because vitamin $\mathrm{D}$ insufficiency is a 
Table 3 Distribution of anthropometry, body composition, biochemical profile and clinical characteristics according to tertile of dietary vitamin D intake among adolescents aged 15 to 17 years, Juiz de Fora city, Brazil

\begin{tabular}{|c|c|c|c|c|c|c|c|}
\hline \multirow[b]{3}{*}{ Variable } & \multicolumn{6}{|c|}{ Dietary vitamin $D$ intake $(\mu \mathrm{g} / \mathrm{d})$} & \multirow[b]{3}{*}{$P$ value } \\
\hline & \multicolumn{2}{|c|}{ 1st tertile } & \multicolumn{2}{|c|}{ 2nd tertile } & \multicolumn{2}{|c|}{ 3rd tertile } & \\
\hline & Mean or median & SD or IQR & Mean or median & SD or IQR & Mean or median & SD or IQR & \\
\hline Weight (kg) & $73 \cdot 3$ & $25 \cdot 2$ & $75 \cdot 5$ & $28 \cdot 2$ & $63 \cdot 9$ & $23 \cdot 7$ & 0.086 \\
\hline Height $(\mathrm{cm}) \dagger$ & $168 \cdot 3$ & $1 \cdot 1$ & $169 \cdot 3$ & $1 \cdot 3$ & $170 \cdot 3$ & $1 \cdot 2$ & 0.525 \\
\hline BMI $\left(\mathrm{kg} / \mathrm{m}^{2}\right)$ & $26 \cdot 6^{a}$ & $8 \cdot 6$ & $25 \cdot 3^{a}$ & $9 \cdot 5$ & $21 \cdot 7^{\mathrm{b}}$ & $6 \cdot \overline{3}$ & $0.016^{*}$ \\
\hline $\mathrm{WC}(\mathrm{cm})$ & $77 \cdot 9^{a}$ & 18 & $79 \cdot 0^{\mathrm{a}}$ & 23 & $70 \cdot 1^{b}$ & 16 & $0.025^{*}$ \\
\hline$\% B F$ & $30 \cdot 2$ & $12 \cdot 2$ & $29 \cdot 6$ & $15 \cdot 1$ & $27 \cdot 2$ & $12 \cdot 2$ & 0.066 \\
\hline $\mathrm{TC}(\mathrm{mg} / \mathrm{dl})+$ & $166 \cdot 4$ & $4 \cdot 6$ & $168 \cdot 1$ & $5 \cdot 1$ & $171 \cdot 6$ & $4 \cdot 2$ & $0 \cdot 722$ \\
\hline HDL-C (mg/dl)† & $50 \cdot 4$ & $1 \cdot 2$ & $49 \cdot 0$ & $1 \cdot 4$ & $51 \cdot 6$ & $1 \cdot 4$ & 0.427 \\
\hline LDL-C (mg/dl) & $92 \cdot 0$ & 43 & $100 \cdot 0$ & 35 & $101 \cdot 5$ & 39 & 0.473 \\
\hline TAG $(\mathrm{mg} / \mathrm{dl})$ & $75 \cdot 0$ & 47 & $68 \cdot 0$ & 41 & $74 \cdot 0$ & 48 & 0.910 \\
\hline Glucose $(\mathrm{mg} / \mathrm{dl}) \dagger$ & $85 \cdot 2$ & $1 \cdot 0$ & $83 \cdot 6$ & $1 \cdot 4$ & $84 \cdot 7$ & $1 \cdot 2$ & 0.651 \\
\hline Insulin (U/ml) & $10 \cdot 3$ & $4 \cdot 7$ & $10 \cdot 3$ & $4 \cdot 9$ & $9 \cdot 4$ & $3 \cdot 0$ & 0.098 \\
\hline HOMA-IR & $2 \cdot 3$ & $1 \cdot 0$ & $2 \cdot 1$ & $1 \cdot 4$ & $1 \cdot 8$ & $1 \cdot 0$ & $0 \cdot 150$ \\
\hline $25(\mathrm{OH}) \mathrm{D}(\mathrm{nmol} / \mathrm{l})$ & $22 \cdot 2$ & $13 \cdot 0$ & $24 \cdot 8$ & $12 \cdot 1$ & $25 \cdot 2$ & $11 \cdot 1$ & 0.293 \\
\hline $\mathrm{PTH}_{\mathrm{i}}(\mathrm{nmol} / \mathrm{l})$ & $39 \cdot 9$ & $20 \cdot 4$ & $46 \cdot 5$ & $21 \cdot 6$ & $41 \cdot 2$ & $21 \cdot 8$ & $0 \cdot 117$ \\
\hline $\mathrm{SBP}(\mathrm{mmHg})+$ & $122 \cdot 0$ & $1 \cdot 9$ & $120 \cdot 8$ & $1 \cdot 7$ & $118 \cdot 1$ & 1.9 & 0.322 \\
\hline DBP (mmHg) & $75 \cdot 0$ & 12 & $73 \cdot 0$ & 11 & $69 \cdot 8$ & 11 & 0.060 \\
\hline
\end{tabular}

IQR, interquartile range; WC, waist circumference; \%BF, percentage of body fat; TC, total cholesterol; HDL-C, HDL-cholesterol; LDL-C, LDL-cholesterol; HOMA-IR, homeostasis model assessment of insulin resistance; $25(\mathrm{OH}) \mathrm{D}$, calcidiol; $\mathrm{PTH}_{\mathrm{i}}$, intact parathyroid hormone; SBP, systolic blood pressure; DBP, diastolic blood pressure.

a,b Mean values within a row with unlike superscript letters were significantly different $(P<0 \cdot 05)$.

${ }^{*}$ Significant result.

tThese variables were parametric (mean and standard deviation) and assessed with ANOVA using the Tukey test for post hoc comparisons; otherwise, variables were non-parametric (median and IQR) and assessed with the Kruskal-Wallis test using the Bonferroni test for post hoc comparisons.

global problem, even in sunny environments like Brazil, and the study is one of the few performed in developing countries that evaluated vitamin D status and its association with metabolic disorders in adolescents. It is unclear whether the association between low serum vitamin $\mathrm{D}$ and metabolic disorders is causal, much less the direction of causality. Low serum vitamin $\mathrm{D}$ is contributing to the increased prevalence of metabolic disorders or metabolic disorders increase the risk of low serum vitamin $\mathrm{D}$, or both. Another limitation is that the present study did not evaluate daily activities in sunlight like walking and driving a car, only physical activities. More detailed information about sun exposure is necessary to investigate the variation of serum concentration of $25(\mathrm{OH}) \mathrm{D}$. It is important to recognize the limitations of dietary assessment when studying the relationship between food intake and adiposity, such as under-reporting. However this information bias did not affect the results in relation to vitamin $\mathrm{D}$ intake, which was lower in adolescents with excess weight, as seen in the literature.

Some strengths of our study should also be considered. First, the inclusion of adolescents with normal and excess weight allows for control of the effect of BMI on clinical and biochemical parameters, and understanding the direct association of vitamin $\mathrm{D}$ on these parameters. Second, the selection of postpubertal adolescents to control biological markers characteristic of late sexual maturation $^{(14,15)}$, such as menarche and the presence of axillary and facial hair, allowed us to reduce the influence of the sexual maturation process on body composition and metabolic changes.

\section{Conclusion}

Our results support the negative association of serum $25(\mathrm{OH}) \mathrm{D}$ levels with non-skeletal outcomes in Brazilian adolescents, such as obesity, abdominal obesity, hypercholesterolaemia, insulin resistance, hyperinsulinaemia and hypertension. Furthermore, lower BMI and WC were observed in the third tertile of vitamin D intake for all adolescents.

Although hypovitaminosis D is lower in Brazil due to the tropical climate, a significant frequency of insufficiency of this vitamin is seen when compared with milder climates. The high frequency of vitamin D insufficiency is primarily nutritional and reflects a low vitamin D intake. Vitamin D fortification of foods and/or the use of vitamin D supplements need to be considered to raise the vitamin $\mathrm{D}$ intake in the adolescent population, even in a sunny country like Brazil.

The present study is one of few performed in developing countries that evaluated vitamin D status and its association with overweight and metabolic disorders in adolescents. These results are useful to health practitioners and should raise concerns in assessment and management of patients/ clients. Randomized clinical trials are of utmost importance to test the effects of vitamin D on non-skeletal outcomes, as well as possible mediating effects of sun exposure, adiposity and genetic factors on this relationship.

\section{Acknowledgements}

Sources of funding: This work was supported by the Fundação de Amparo a Pesquisa do Estado de Minas 
Gerais (FAPEMIG) under grant number 01571-09. Conflicts of interest: The authors declare no conflict of interest. Ethical information: The study was conducted according to the guidelines laid down in the Declaration of Helsinki and all procedures involving human subjects/ patients were submitted to and approved by the Ethics Committee of the Universidade Federal de Juiz de Fora. Study participants and their guardians were informed about the study objectives. Participation was voluntary and was allowed only after signing of an informed consent by parents or guardians. Authors' contributions: All of the authors have participated sufficiently in the conception and design of this work and the analysis of the data, as well as the writing of the manuscript, to take public responsibility for it. Acknowledgements: The authors thank FAPEMIG for financing the project, the Nutrition Department of the Federal University of Juiz de Fora for support and the adolescents for their participation in the study.

\section{References}

1. Forrest KYZ, Stuhldreher WL \& Kimberly YZ (2011) Prevalence and correlates of vitamin D deficiency in US adults. Nutr Res 31, 48-54.

2. Kimbal S, Fuleihan Gel-H \& Vieth R (2008) Vitamin D: a growing perspective. Crit Rev Clin Lab Sci 45, 339-414.

3. Binkley N, Ramamurthy R \& Krueger D (2010) Low vitamin D status: definition, prevalence, consequences, and correction. Endocrinol Metab Clin North Am 39, 287-301.

4. Holick MF (2004) Sunlight and vitamin D for bone health and prevention of autoimmune diseases, cancers, and cardiovascular disease. Am J Clin Nutr 80, Suppl. 6, S1678-S1688.

5. Peters BS, dos Santos LC, Fisberg M et al. (2009) Prevalence of vitamin D insufficiency in Brazilian adolescents. Ann Nutr Metab 54, 15-21.

6. Borges MC, Martini LA \& Rogero MM (2011) Current perspectives on vitamin $\mathrm{D}$, immune system, and chronic diseases. Nutrition 27, 399-404.

7. Foss YJ (2009) Vitamin D deficiency is the cause of common obesity. Med Hypotheses 72, 314-321.

8. Harel Z, Flanagan P, Forcier M et al. (2011) Low vitamin D status among obese adolescents: prevalence and response to treatment. J Adolesc Health 48, 448-452.

9. Kelly A, Brooks LJ, Dougherty S et al. (2011) A crosssectional study of vitamin D and insulin resistance in children. Arch Dis Child 96, 447-452.

10. World Health Organization (2005) Nutrition in Adolescence: Issues and Challenges for the Health Sector. Issues in Adolescent Health and Development. Geneva: WHO.

11. Lloyd LJ, Langley-Evans SC \& McMullen S (2010) Childhood obesity and adult cardiovascular disease risk: a systematic review. Int J Obes (Lond) 34, 18-28.

12. Instituto Brasileiro de Geografia e Estatística (2010) Pesquisa de Orçamentos Familiares 2008-2009. Antropometria e estado nutricional de crianças, adolescentes e adultos no Brasil. http://www.ibge.gov.br/home/estatistica/ populacao/condicaodevida/pof/2008_2009_encaa/pof_ 20082009_encaa.pdf (accessed September 2010).

13. Instituto Brasileiro de Geografia e Estatística (2012) Censo demográfico 2010. http://www.ibge.gov.br/home/ estatistica/populacao/censo2010/default.shtm (accessed September 2012).
14. Instituto Nacional de Estudos e Pesquisas Educacionais Anísio Teixeira (2009) Data escola Brasil. http://www. dataescolabrasil.inep.gov.br/dataEscolaBrasil/home.seam (accessed July 2010).

15. Colli AS (1985) Maturación sexual de los adolescents de São Paulo. In La Salud del Adolescent y el Jovem em las Americas, pp. 249-258 [M Maddaleno, MM Munist, CV Serrano et al., organizers]. Washington, DC: Organización Pan Americana de la Salud.

16. Colli AS, Coates V \& Guimarães BEM (1993) Monitoração do crescimento e desenvolvimento físico. In Medicina do Adolescente, pp. 51-65 [V Coates, editor]. São Paulo: Sarvier.

17. Jelliffe DB (1968) Evaluación del estado de nutrición de la comunidad. Ginebra: Organização Mundial de Saúde.

18. de Onis M, Onyango AW, Borghi E et al. (2007) Development of a WHO growth reference for school-aged children and adolescents. Bull World Health Organ 85, 660-667.

19. International Diabetes Federation (2007) The IDF consensus definition of the Metabolic Syndrome in children and adolescents. http://www.idf.org/webdata/docs/Mets_ definition_children.pdf (accessed March 2012).

20. Biodynamics Corporation (2013) Biodynamics BIA 310 Bioimpedance Analyzer: manual. http://www.biodyncorp. com/tools/test_protocol.html (accessed April 2013).

21. Houtkooper LB, Lohman TG, Going SB et al. (1989) Validity of bioelectric impedance for body composition assessment in children. J Appl Physiol 66, 814-821.

22. Lohman TG (1992) (editor) Assessing fat distribution. In Advances in Body Composition Assessment: Current Issues in Exercise Science, pp. 57-63. Champaign, IL: Human Kinetics.

23. Sociedade Brasileira de Cardiologia (2005) I diretriz de prevenção da aterosclerose na infância e na adolescência. Arq Bras Cardiol 85, Suppl. 6, S3-S36.

24. American Diabetes Association (2006) Diagnosis and classification of diabetes mellitus. Diabetes Care 29, Suppl. 1, S43-S48.

25. Bischoff-Ferrari HA, Giovannucci E, Willett WC et al. (2006) Estimation of optimal serum concentrations of 25-hydroxyvitamin D for multiple health outcomes. Am J Clin Nutr 84, $18-28$.

26. El Assaad MA, Topouchian JA, Darné BM et al. (2002) Validation of the Omron HEM-907 device for blood pressure measurement. Blood Press Monit 7, 237-241.

27. Sociedade Brasileira de Cardiologia, Sociedade Brasileira de Hipertensão \& Sociedade Brasileira de Nefrologia (2010) VI diretrizes brasileiras de hipertensão arterial. Arq Bras Cardiol 95, Suppl. 1, 1-5.

28. Willett W \& Stampfer M (1998) Implications of total energy intake for epidemiological analyses. In Nutritional Epidemiology, 2nd ed., pp. 273-301 [W Willett, editor]. New York: Oxford University Press.

29. Philippi ST (2002) Tabela de Composição de Alimentos: Suporte para Decisão Nutricional, 2nd ed. Brasília: ANVISA.

30. Pinheiro ABV, Lacerda EMA, Benzecry EH et al. (2004) Tabela de Composição de Alimentos. São Paulo: Ed. Atheneu.

31. Institute of Medicine (1999) Dietary Reference Intakes for Calcium, Phosphorus, Magnesium, Vitamin D, and Fluoride. Washington, DC: National Academy Press.

32. Florindo AA, RomeroII A, Peres SV et al. (2006) Desenvolvimento e validação de um questionário de avaliação da atividade física para adolescentes. Rev Saude Publica 40, 802-809. 
33. Pate RR, Freedson PS, Sallis JF et al. (2002) Compliance with physical activity guidelines: prevalence in a population of children and youth. Ann Epidemiol 12, 303-308.

34. Institute of Medicine (2001) Dietary Reference Intakes for Energy, Carbohydrate, Fiber, Fat, Fatty Acids, Cholesterol, Protein, and Amino Acids (Macronutrients). Washington, DC: National Academy Press.

35. Delvin EE, Lambert M, Levy E et al. (2010) Vitamin D status is modestly associated with glycemia and indicators of lipid metabolism in French-Canadian children and adolescents. J Nutr 140, 987-991.

36. Snijder MB, Van Dam RM, Visser M et al. (2005) Adiposity in relation to vitamin $\mathrm{D}$ status and parathyroid hormone levels: a population-based study in older men and women. J Clin Endocrinol Metab 90, 4119-4123.

37. Celermajer DS \& Ayer JGJ (2006) Childhood risk factors for adult cardiovascular disease and primary prevention in childhood. Heart 92, 1701-1706.

38. Hill TR, Cotter AA, Mitchell S et al. (2008) Vitamin D status and its determinants in adolescents from the Northern Ireland Young Hearts 2000 cohort. Br J Nutr 99, 1061-1067.

39. Ross AC, Manson JE, Abrams SA et al. (2011) The 2011 Dietary Reference Intakes for calcium and vitamin D: what dietetics practitioners need to know. J Am Diet Assoc 111, 524-527.

40. Au LE, Economos CD, Goodman E et al. (2012) Vitamin D intake and serum vitamin D in ethnically diverse urban schoolchildren. Public Health Nutr 15, 2047-2053. 